\title{
Dizziness and health-related quality of life among older adults in an urban population: a cross-sectional study
}

\author{
Ellen Lindell ${ }^{1,2^{*}} \mathbb{D}$, Lena Kollén ${ }^{2,3}$, Mia Johansson ${ }^{2,4}$, Therese Karlsson ${ }^{1,2}$, Lina Rydén ${ }^{5}$, \\ Madeleine Mellqvist Fässberg ${ }^{5}$, Hanna Falk Erhag ${ }^{5}, \operatorname{Ingmar}$ Skoog ${ }^{5}$ and Caterina Finizia ${ }^{1,2}$
}

\begin{abstract}
Background: Dizziness is a common complaint among older adults and may affect quality of life in a negative way. The aim of this study was to assess health-related quality of life (HRQL), sense of coherence (SOC), self-rated health (SRH) and comorbidity in relation to dizziness, among older persons from an urban population.

Methods: The study is part of the Gothenburg H70 Birth Cohort Studies (H70). A cross-sectional population-based sample including 66279 -years-olds (404 women, 258 men, 62\% response rate) were surveyed with questions regarding dizziness, imbalance, comorbidities and general health. HRQL was assessed using the 36-item Short Form-36 Health Survey (SF-36) and SOC with the 13-items questionnaire Sense of Coherence (SOC-13).

Results: Half of the participants reported problems with dizziness (54\%). Dizziness was negatively associated with $H R Q L$, including after adjusting for comorbidities, especially in the physical domains of SF-36. Having dizziness was also associated with poorer SRH, tiredness and comorbidity among both men and women. SOC (mean total score), however, did not differ between dizzy and non-dizzy participants.

Conclusions: Dizziness was negatively associated with $\mathrm{HRQL}$, also after adjusting for comorbidities. Identification and treatment of dizziness, when possible, are important because reduction of dizziness symptoms may potentially help to enhance overall well-being in this age group.
\end{abstract}

Keywords: Dizziness, Aged, Health-related quality of life, Sense of coherence, Self-rated health, Quality of Life

\section{Background}

Dizziness is a common complaint among older individuals. Approximately one third have impairment of balance or dizziness at age 75 and reports of dizziness increase with advanced age $[1,2]$. Dizziness among older adults may have multiple etiologies, is often associated with

\footnotetext{
*Correspondence: ellen.lindell@gu.se

${ }^{1}$ Department of Otorhinolaryngology, Head and Neck Surgery, Institute of Clinical Sciences, Sahlgrenska Academy, Sahlgrenska Universitetssjukhuset, Gothenburg University, Gröna Stråket 5, 413 45 Gothenburg, Sweden

Full list of author information is available at the end of the article
}

comorbidity and frailty, and is sometimes viewed as part of the geriatric syndrome and aging [3-5].

Worldwide, life expectancy has grown remarkably during the last two decades and is presently 84 years in women and 80 years in men in Sweden [6]. By 2060, approximately one-fourth of the Swedish population is estimated to be over 65 years [6]. With an aging population, prevalence of dizziness and unsteadiness is likely to become more frequent in the forthcoming years. Reasons for having dizziness in higher ages can be many where benign peripheral vestibular disorder and decreased postural control can be affected and impact balance or induce dizziness. With higher age, factors affecting original author(s) and the source, provide a link to the Creative Commons licence, and indicate if changes were made. The images or other third party material in this article are included in the article's Creative Commons licence, unless indicated otherwise in a credit line to the material. If material is not included in the article's Creative Commons licence and your intended use is not permitted by statutory regulation or exceeds the permitted use, you will need to obtain permission directly from the copyright holder. To view a copy of this licence, visit http://creativecommons.org/licenses/by/4.0/. The Creative Commons Public Domain Dedication waiver (http://creativecommons.org/publicdomain/zero/1.0/) applies to the data made available in this article, unless otherwise stated in a credit line to the data. 
balance such as multimorbidity, neuropathy, stroke, cardio vascular disease and impairment of joints like back pain become more common. Having dizziness can be a frightening condition and may increase risk of falls as well as enhance fear of falling and affect quality of life [7, 8]. Furthermore, with higher life expectancy and longer lives, health-related quality of life (HRQL) may become a key outcome in surveys investigating older people.

HRQL is a multidimensional construct and used as an indicator of broad physical and mental health. It specifically refers to the physical, psychological and social domains of health, seen as distinct areas that are influenced by a person's experiences, beliefs, expectations and perceptions $[9,10]$. HRQL can be used to monitor changes of a disease as well as to assess the impact of illness burden of clinical conditions within general populations $[11,12]$.

The ability to stand and move safely is essential for living independently. Having dizziness, as well as impaired balance, influences functional abilities such as moving around or walking and the inability to move safely may induce fear of losing balance and falling [13]. Having dizziness has been shown to correlate with increased number of comorbidities and reduced HRQL [3, 5, 1418]. Enhanced fitness level and being physically active, on the other hand, are associated with higher HRQL among older people [14, 19], meanwhile those with dizziness have been found to be less physically active and to have more diseases $[3,20]$. Whether the reduction in HRQL is due to comorbidities, the dizziness symptom, or less physical performance is unclear. The Short-form 36 Health Survey (SF-36) is one of the most used instruments to assess HRQL worldwide and has been proven useful in monitoring health, estimating burdens of diseases, and evaluating medical treatment effects [21].

Self-rated health (SRH) is also a widely used, albeit more poorly understood, measurement when evaluating health. SRH is based on asking individuals to evaluate their global health status on a four- or five-point scale, although the exact wordings and response options may vary $[22,23]$. There is widespread agreement that this simple global question provides a useful summary of how older people perceive their overall health status, and in some cases, SRH has turned out to be a better predictor of mortality than objective health indicators [24, 25]. SRH can be seen as a sensitive, but non-specific way, to assess health and predict outcomes [26].

Antonovsky developed the theory of sense of coherence (SOC) in the 1970s focusing on factors that support human health and well-being. SOC refers to the ability to utilize internal and external resources to cope with stressors and maintain health. The concept aims to explain how people remain healthy rather than become ill. Antonovsky introduced three components: Comprehensibility, the extent to which one perceives events as making sense; Manageability, the extent to which one feels he or she can cope; and Meaningfulness, the extent to which one feels that life makes sense and that challenges are worthy of commitment. A high SOC has been shown to promote health and even reduce mortality and is related to good health especially in the mental dimension $[27,28]$.

Only a few studies have focused on dizziness in relation to HRQL and SOC [29, 30], where investigations are carried out on patients seeking medical care in balance clinics. A Swedish survey of patients suffering from vestibular disorders showed an association between unsteadiness, fall tendency and lower scores on SOC [29]. None of the studies on SOC and dizziness have been population-based, targeting older people with general dizziness/unsteadiness.

The aim of this study was to assess HRQL, SOC, SRH and comorbidity in relation to dizziness among older men and women in an urban population.

\section{Methods \\ Study population}

This study was part of the fifth cohort of the geriatric population-based Gothenburg H70 Birth Cohort Studies, that studies health-related factors in older adults. Persons were selected from an urban population born in 1930 through systematic sampling based on date of birth using the Swedish National Population Register. Invited people included those living in either ordinary or special housing. A total of 1063 individuals (659 women, 404 men), all aged 79 years old, were invited to participate and 662 individuals (404 women and 258 men; $62 \%$ response rate) agreed to participate in the multidisciplinary survey. The study was conducted in 2009-2010. The participants were interviewed by a research nurse or physician at the neuropsychiatric outpatient clinic at Sahlgrenska University Hospital in Gothenburg, Sweden, or in the participants' home.

\section{Dizziness}

Study-specific questions concerned dizziness, general health and tiredness. The main variable was the question concerning dizziness: "Do you have any problems with dizziness, impaired balance or unsteadiness?". The response alternatives were yes/no. If "yes", further questions included; "Duration of dizziness?" (seconds/minutes/hours); "For how long have you had dizziness?" ( $<6$ months, 6 months -2 years, $>2$ years). "Do you have such dizziness that it hinders you in your daily activities? (yes/no). Dizziness triggered by; "Rising from supine to sitting position?" (yes/no), "When lying on the side?" 
(yes/no). "When turning the head?" (yes/no), "When you exercise? (yes/no), "By positional changes?" (yes/no). A total of 647 people (395 women, 252 men) answered the questions regarding dizziness and were included in this study. All questions and questionnaire were in Swedish language.

\section{Characteristics of the participants}

The participants were asked about their current marital status, type of living, if they were dependent on help in activities of daily living (ADL) and instrumental activities of daily living (IADL) according to ten different functions from the Katz scale [31].

\section{HRQL}

HRQL was assessed with SF-36 which consists of 36 questions distributed over eight subscales: physical function $(\mathrm{PF})$, role limitation due to physical problems (RP), bodily pain (BP), general health $(\mathrm{GH})$, vitality $(\mathrm{VT})$, social function (SF), role limitation due to emotional problems (RE) and mental health (MH) [21]. Every component is standardized and the scores range from 0 (worst) to 100 (best). Low scores represent low HRQL. The SF-36 is a widely used instrument for measuring self-perceived physical and mental health status. Validity and reliability have been evaluated and confirmed in prior studies [32]. The instrument is translated to Swedish and has been validated in a representative sample of the population [33]. In this study a total of 471 participants (284 women, 187 men) answered the SF-36 questionnaire and mean and standard deviation (SD) was calculated for every domain of the SF-36.

\section{SOC}

The SOC instrument was developed by Antonovsky to measure overall coping capacity during stressful situations and circumstances in life [34]. The 13 items questionnaire (SOC-13) used in this study is a shorter version of the original 29-item instrument. It is used to study three domains, namely; comprehensibility, manageability and meaningfulness. The total score ranges from 13 to 91 where each question is scored on a 7-point scale. The higher the score, the stronger the SOC. The validity of the questionnaire is reported to be acceptable and testretest stable [35]. In this study a total of 452 participants (272 women, 180 men) answered the SOC-13.

\section{SRH, tiredness and comorbidity}

SRH was measured using the question, "How is your general health?" with response options ranging from "very good", "good", "poor" to "very poor". In addition, respondents also answered whether they felt well or generally tired (yes/no). Regarding diseases, the participants were asked about current conditions and diseases: "Have you been told by a medical doctor or nurse that you have or have had, any of the following diseases or disorders?" and were asked according to a list of conditions including: diabetes, hypertension, hyper or hypothyroidism, lung disease (chronic bronchitis, asthma, chronic obstructive pulmonary disease), cardiac infarction/heart failure, prior stroke, vision and hearing impairment and joint/ back problems.

\section{Statistical methods}

Mean, median and 95\% confidence intervals (CI) or standard deviation (SD) of the mean were used for descriptive purposes. Mean and CI or SD were used for continuous variables while number and percent were used for categorical variables. Tests of differences between the group with and without dizziness, and between men and women included Fisher's exact test and logistic regression for dichotomous variables, MantelHaenszel chi square test for ordered variables, Chi square test for non-ordered variables and $t$ tests for continuous variables. Significance was always reported for two-tailed tests and the significance level used was $5 \%$.

Backward multivariable linear regression was conducted $(p<0.01)$ to identify factors and conditions influencing HRQL (SF-36 domains, 8 domains) as dependent variables. Beta-estimate, $\mathrm{CI}, p$ value and $\mathrm{R}$-square were presented. The software used for the statistical analysis was SPSS 24 or a statistics program package developed at the Department of Geriatrics at University of Gothenburg (GIDSS for Windows).

\section{Ethical considerations}

The study was conducted according to the Declaration of Helsinki and was approved by the Regional Ethical Review Board in Gothenburg, Sweden. All participants gave their informed written consent before inclusion in the study.

\section{Results \\ Dizziness and unsteadiness}

More than half of the sample of 79-year-olds reported problems with dizziness or unsteadiness and no significant differences in prevalence were observed between men and women $(n=125,50 \%$ of the men; $n=222$, $56 \%$ of the women; $p=0.12$ ). The majority of the participants with dizziness reported problems with dizziness for more than six months $(82 \%$ of the women, $78 \%$ of the men) and more than half of the participants with dizziness reported problems with dizziness daily or weekly (56\% of the women, $57 \%$ of the men). Dizziness lasting for only seconds was the most common duration $(n=54,65 \%$ of the men; $n=90,65 \%$ of the 
women) whereas dizziness lasting minutes $(n=20$, $14 \%$ of the women; $n=16,20 \%$ of the men) or hours $(\mathrm{n}=28,20 \%$ of the women; $\mathrm{n}=12,15 \%$ of the men) where not so common, also reported elsewhere [18]. Dizziness triggered by rising up from supine position was the most common symptom $(n=46,61 \%$ of the men; $n=68,50 \%$ of the women) followed by dizziness triggered by positional changes $(n=24,34 \%$ of the men; $n=48,38 \%$ of the women) and by turning the head ( $n=16,24 \%$ of the men; $n=26,22 \%$ of the women). More than one quarter of the participants with dizziness $(n=22,23 \%$ of the men, $n=48,31 \%$ of the women) reported that dizziness had an impact on their daily activities and about one fifth $(n=13,19 \%$ of the men; $n=24,20 \%$ of the women) reported dizziness by physical exercise. Dizziness when lying on the side was reported by 8 women (7\%) and $2(3 \%)$ men.

\section{Characteristics}

There was no significant difference in type of housing or marital status between dizzy and non-dizzy individuals (Table 1). Persons with dizziness had higher levels of IADL dependency than persons without dizziness (Table 1). Some sex differences were seen between the distribution of diseases where a greater percentage of men had vascular diseases (stroke, heart disease) and a greater percentage of women reported thyroid disease and joint/back pain (Table 2).

HRQL

Being dizzy was negatively associated with HRQL. The negative association between dizziness and HRQL was seen for every domain except RE among women and $\mathrm{MH}$ among men, with the largest impact in the physical domains (Table 3). After adjustment for diseases and conditions, being dizzy still had significant impact on HRQL measured with SF-36 in five domains (PF, BP, GH, VT,

Table 1 Characteristics of study population

\begin{tabular}{|c|c|c|c|c|c|c|}
\hline & \multicolumn{2}{|c|}{ Women $(n=395)$} & \multicolumn{2}{|l|}{ Men $(n=252)$} & \multicolumn{2}{|c|}{ Women and men $(n=647)$} \\
\hline & $\begin{array}{l}\text { No dizziness } \\
n=173\end{array}$ & $\begin{array}{l}\text { Dizziness } \\
\mathrm{n}=\mathbf{2 2 2}\end{array}$ & $\begin{array}{l}\text { No dizziness } \\
n=127\end{array}$ & $\begin{array}{l}\text { Dizziness } \\
n=125\end{array}$ & $\begin{array}{l}\text { No dizziness } \\
n=300\end{array}$ & $\begin{array}{l}\text { Dizziness } \\
\mathrm{n}=\mathbf{3 4 7}\end{array}$ \\
\hline \multicolumn{7}{|l|}{ Marital status, $n(\%)$} \\
\hline Single & $18(11)$ & $12(6)$ & $14(11)$ & $13(10)$ & $32(11)$ & $25(7)$ \\
\hline Married & $57(33)$ & $74(34)$ & $89(70)$ & $82(65)$ & $146(49)$ & $156(46)$ \\
\hline Divorced & $23(13)$ & $35(16)$ & $7(6)$ & $10(8)$ & $30(10)$ & $45(13)$ \\
\hline Widow & $73(43)$ & $95(44)$ & $17(13)$ & $20(16)$ & $90(30)$ & $115(34)$ \\
\hline \multicolumn{7}{|l|}{ Type of housing, $n(\%)$} \\
\hline Apartment & $115(67)$ & $145(56)$ & $70(56)$ & $74(60)$ & $185(63)$ & $219(65)$ \\
\hline Private house & $51(30)$ & $60(28)$ & $53(42)$ & $47(38)$ & $104(35)$ & $107(32)$ \\
\hline Sheltered living & $5(3)$ & $9(4)$ & $2(2)$ & $3(2)$ & $7(2)$ & $12(4)$ \\
\hline \multicolumn{7}{|c|}{ Dependent in help with, $n$ (\%) } \\
\hline Cleaning the house & $28(16)$ & $61(29)^{* *}$ & $22(17)$ & $29(23)^{* *}$ & $50(17)$ & $90(26)^{* *}$ \\
\hline Shopping & $24(14)$ & $37(17)$ & $8(6)$ & $22(18)^{* *}$ & $32(11)$ & $59(17) *$ \\
\hline Transport & $23(13)$ & $40(18)$ & $6(5)$ & $17(14)^{*}$ & $29(10)$ & $57(17)^{*}$ \\
\hline Cooking & $12(7)$ & $16(7)$ & $7(6)$ & $18(15)^{*}$ & $19(6)$ & $34(10)$ \\
\hline Bathing & $12(7)$ & $18(8)$ & $3(2)$ & $12(10)^{*}$ & $15(5)$ & $30(9)$ \\
\hline Dressing & $11(6)$ & $6(3)$ & $2(2)$ & $5(4)$ & $13(4)$ & $11(3)$ \\
\hline Toileting & $6(3)$ & $3(1)$ & $2(2)$ & $3(2)$ & $8(3)$ & $6(2)$ \\
\hline Transferring & $4(2)$ & $4(2)$ & $2(2)$ & $1(1)$ & $6(2)$ & $5(1)$ \\
\hline Continence & $7(4)$ & $8(4)$ & $3(2)$ & $3(2)$ & $10(3)$ & $11(3)$ \\
\hline Eating & $2(1)$ & $2(1)$ & $1(1)$ & 0 & $3(1)$ & $2(1)$ \\
\hline \multicolumn{7}{|c|}{ Number of $A D L^{\mathrm{a}}$ dependency } \\
\hline 0 & $141(82)$ & $151(69)$ & $104(83)$ & $92(74)$ & $245(82)$ & $243(71)$ \\
\hline 1 & $10(6)$ & $34(16)$ & $13(10)$ & $7(35)$ & $23(8)$ & $41(12)$ \\
\hline $2-3$ & $9(5)$ & $20(9)$ & $6(5)$ & $16(73)$ & $15(5)$ & $36(10)$ \\
\hline \multirow[t]{2}{*}{$4-8$} & $12(7)$ & $14(6)$ & $3(2)$ & $9(75)$ & $15(5)$ & $23(7)$ \\
\hline & & ns & & $p<0.05$ & & $p<0.01$ \\
\hline
\end{tabular}

${ }^{a} A D L$ activities of daily living. $p$ values based on and Fisher's exact test (dependence of help for ADL and instrumental ADL), Chi square test (marital status, type of housing) and Mantel-Haenszel chi square test (number of ADL dependencies), comparing dizzy and non-dizzy individuals, ${ }^{*} p<0.05,{ }^{* *} p<0.01,{ }^{* * *} p<0.001$ 
Table 2 Frequency of conditions and diseases among men and women in the study cohort

\begin{tabular}{lccl}
\hline & $\begin{array}{l}\text { Women }(\mathbf{n}=\mathbf{3 9 5}) \\
\text { Frequency, } \mathbf{n}(\%)\end{array}$ & $\begin{array}{l}\text { Men }(\mathbf{n}=\mathbf{2 5 2}) \\
\text { Frequency, } \mathbf{n}(\%)\end{array}$ & $\boldsymbol{p}$ value \\
\hline Diabetes & $49(12)$ & $41(16)$ & 0.2 \\
Hypertension & $228(57)$ & $152(59)$ & 0.6 \\
Thyroid disease & $62(15)$ & $15(6)$ & 0.001 \\
Lung disease & $51(13)$ & $31(12)$ & 0.8 \\
Heart disease & $89(22)$ & $82(32)$ & 0.008 \\
Stroke/TIA & $65(16)$ & $62(24)$ & 0.015 \\
Vision impairment & $114(28)$ & $73(28)$ & 1.0 \\
Hearing impairment & $120(30)$ & $86(33)$ & 0.4 \\
Joint/back problems & $198(49)$ & $102(40)$ & 0.02 \\
\hline
\end{tabular}

${ }^{a}$ TIA transient ischemic attack. $p$ values comparing differences between men and women and SF) (Table 4). Joint/back problems and vision were the factors influencing HRQL the most in the regression analyses (Table 5). Men had slightly higher scores compared to women on all SF-36 subscales, but significant sex differences were only seen in the PF $(p<0.01)$, BP $(p<0.01)$, and MH $(p<0.05)$ domains (Table 6).

SOC

There was no significant difference between dizzy and non-dizzy individuals in mean total scores of the SOC13, nor when analyzing the subdomains, comprehensibility, manageability or meaningfulness, separately (Table 3). No sex differences regarding mean total score were observed $(p=0.94)$. In multiple linear regression, an association was observed between SOC and HRQL in all SF-36 domains except PF (Table 5).

Table 3 HRQL (SF-36), SOC (SOC-13), SRH and tiredness among women and men with and without dizziness

\begin{tabular}{|c|c|c|c|c|c|c|}
\hline & \multicolumn{2}{|l|}{ Women } & \multicolumn{2}{|l|}{ Men } & \multicolumn{2}{|c|}{ Women and men } \\
\hline & No dizziness & Dizziness & No dizziness & Dizziness & No dizziness & Dizziness \\
\hline \multicolumn{7}{|l|}{ SF-36, mean (SD) } \\
\hline $\mathrm{n}=$ & 132 & 152 & 94 & 93 & 226 & 245 \\
\hline \multicolumn{7}{|l|}{ Physical functioning } \\
\hline Role physical & $69.7(24.6)$ & $57.2(24.0) * * *$ & $77.6(20.0)$ & $65.6(24.0) * *$ & $73.0(23)$ & $60.3(24.9) * * *$ \\
\hline Bodily pain & $65.5(41.6)$ & $52.2(44.0) * *$ & $73.8(37.6)$ & $55.6(42.1)^{* *}$ & $69.0(40.0)$ & $53.5(43.3) * * *$ \\
\hline General health & 70.9 (27.3) & $53.0(24.1)^{* * *}$ & $76.7(25.3)$ & $65.0(27.3)^{* *}$ & $73.3(26.7)$ & $57.5(25.9) * * *$ \\
\hline Vitality & $70.0(18.7)$ & $56.5(20.6) * * *$ & $68.1(18.7)$ & $60.6(21.5) *$ & $69.2(18.7)$ & $58.0(20.0) * * *$ \\
\hline Social functioning & $68.1(21.6)$ & $55.1(24.4) * * *$ & $70.6(20.6)$ & $59.7(23.1) * *$ & $69.2(21.2)$ & $56.8(23.9) * * *$ \\
\hline Role emotional & $86.3(20.1)$ & $76.3(25.7)^{* *}$ & $87.8(20.3)$ & $81.1(25.0) *$ & $86.9(20.6)$ & $78.1(25.5) * * *$ \\
\hline \multirow[t]{2}{*}{ Mental health } & $76.1(39.1)$ & $67.6(40.5)$ & $79.6(33.0)$ & $68.4(39.7)^{*}$ & $77.6(36.7)$ & $67.9(40.1) * *$ \\
\hline & $80.9(18.3)$ & $73.0(21.8)^{* *}$ & $84.5(17.5)$ & $80.7(16.0)$ & $82.4(18.0)$ & $75.9(20)^{* *}$ \\
\hline \multicolumn{7}{|l|}{ SOC-13, mean (SD) } \\
\hline $\mathrm{n}=$ & 126 & 146 & 98 & 82 & 228 & 224 \\
\hline SOC-13 total & $75.4(11.1)$ & $74.2(10.3)$ & 75.7 (8.37) & $74.7(9.31)$ & 75.5 (9.99) & 74.4 (9.97) \\
\hline \multicolumn{7}{|l|}{ SOC: } \\
\hline Comprehensibility & $28.0(4.60)$ & $28.0(4.26)$ & $28.7(3.59)$ & $28.0(3.95)$ & $28.3(4.19)$ & $28.0(4.15)$ \\
\hline Manageability & $23.0(3.96)$ & $22.6(3.51)$ & $23.0(3.07)$ & $22.9(3.01)$ & $23.0(3.59)$ & $22.7(3.34)$ \\
\hline Meaningfulness & $24.2(4.61)$ & $24.0(4.20)$ & $24.6(3.09)$ & $23.8(4.19)$ & $24.4(4.02)$ & $23.8(4.19)$ \\
\hline \multicolumn{7}{|c|}{ SRH and tiredness, $n(\%)$} \\
\hline Very good & $54(32)$ & $22(10)$ & $39(31)$ & $12(10)$ & $93(31)$ & $34(10)$ \\
\hline Good & $103(61)$ & $154(70)$ & $79(63)$ & $95(77)$ & $182(62)$ & $249(72)$ \\
\hline Pretty poor & $12(7)$ & $39(18)$ & $6(5)$ & $14(11)$ & $18(6)$ & $53(16)$ \\
\hline \multirow[t]{2}{*}{ Very poor } & $1(1)$ & $5(2)$ & $2(2)$ & $3(2)$ & $3(1)$ & $8(2)$ \\
\hline & & $p<0.0001$ & & $p<0.001$ & & $p<0.0001$ \\
\hline Not feeling well & $22(13)$ & $62(29) * *$ & $15(12)$ & $31(25)^{* *}$ & $37(13)$ & $93(27)^{* * *}$ \\
\hline Feeling tired & $61(36)$ & $113(52) * *$ & $35(28)$ & $57(46) * *$ & $96(32)$ & $170(50)^{* * *}$ \\
\hline
\end{tabular}

Health-related quality of life (HRQL) measured with Short form Health Survey questionnaire (SF-36), Sense of coherence (SOC-13), self-rated health (SRH) and tiredness among women and men with and without dizziness

$p$ values based on $t$ test (SF-36, SOC-13), Mantel-Haenszel chi square test (SRH) and Fisher's exact test (feeling tired, not feeling well), comparing dizzy and non-dizzy individuals (SF-36, SOC-13), ${ }^{*} p<0.05,{ }^{* *} p<0.01,{ }^{* * *} p<0.001$.

The maximum score for SF-36 is 100 for every domain, higher scores indicate better HRQL. The maximum total score for SOC-13 is 91 (range $13-91$ ), higher scores indicate higher sense of coherence 
Table 4 Difference in mean in the domains of the Short form Health Survey questionnaire (SF-36)

\begin{tabular}{|c|c|c|c|c|c|c|c|c|}
\hline & $\begin{array}{l}\text { Physical } \\
\text { functioning }\end{array}$ & Role physical & Bodily pain & General health & Vitality & $\begin{array}{l}\text { Social } \\
\text { functioning }\end{array}$ & $\begin{array}{l}\text { Role } \\
\text { emotional }\end{array}$ & Mental health \\
\hline \multicolumn{9}{|c|}{$\begin{array}{l}\text { Dizziness, unad- } \\
\text { justed }\end{array}$} \\
\hline Mean & -12.4 & -15.1 & -15.5 & -11 & -12.3 & -8.5 & -9.1 & -6.3 \\
\hline $\mathrm{Cl}^{\mathrm{a}}$ & $-8.1,-16.8$ & $-7.5,-22.7$ & $-10.7,-20.3$ & $-7.3,-14.6$ & $-8.2,-16.4$ & $-4.3,-12.7$ & $-2.0,-12.7$ & $-2.8,-9.7$ \\
\hline$p$ value & $<0.0001$ & 0.0001 & $<0.0001$ & $<0.0001$ & $<0.0001$ & 0.0001 & 0.0001 & 0.0004 \\
\hline \multicolumn{9}{|c|}{$\begin{array}{l}\text { Dizziness, } \\
\text { adjusted }^{*}\end{array}$} \\
\hline Mean & -6 & -7.4 & -8.2 & -4.2 & -6.4 & -4.9 & -5.4 & -2.7 \\
\hline $\mathrm{Cl}$ & $-10.3,-1.6$ & $-15.5,-0.7$ & $-12.6,-3.6$ & $-7.6,-0.5$ & $-10.4,-2.4$ & $-9.3,-0.5$ & $-13,-2.1$ & $-6.0,-0.7$ \\
\hline$p$ value & 0.007 & 0.07 & 0.0005 & 0.02 & 0.002 & 0.03 & 0.2 & 0.1 \\
\hline
\end{tabular}

Difference in mean in the domains of the Short form Health Survey questionnaire (SF-36) measuring health-related quality of life between dizzy and no dizzy participants, unadjusted and adjusted* ${ }^{*}$ values

${ }^{a} \mathrm{Cl}$ confidence interval

*Adjusted for sex, sense of coherence (SOC)-13 total score, diabetes, hypertension, hypothyroidism, lung disease (chronic obstructive pulmonary disease, asthma, chronic bronchitis), heart disease, stroke/transient ischemic attack, vision impairment, hearing impairment, joint problems and sum of seven diseases in a linear regression

\section{SRH and tiredness}

A total of $73 \%$ of the dizzy participants reported feeling well, compared to $87 \%$ of the non-dizzy participants (Table 3). Half of the participants reporting dizziness (50\%) felt generally tired compared to about one-third $(32 \%)$ of the non-dizzy participants $(p<0.001)$ (Table 3$)$. The odds ratio of feeling tired if reporting dizziness was 2.13 (CI 1.54-2.93, $p<0.0001$ ) and 2.65 (CI 1.75-4.04, $p<0.0001)$ for not feeling well if reporting dizziness.

\section{Discussion}

The aim of this study was to assess dizziness in relation to HRQL SOC, SRH and diseases among older adults living in an urban area in Sweden. We found that dizzy seniors were more tired and considered their HRQL and health to be poorer than non-dizzy seniors. There was a distinct difference in HRQL between dizzy and non-dizzy persons, where dizziness was associated with poorer HRQL particularly in the aspects of physical health.

In this study we found that HRQL was negatively influenced by having dizziness and dizziness together with joint/back problems and vision impairment were the conditions influencing HRQL the most in multivariate analyses. Having joint/back problems as well as vision impairment (cataracts) may themselves result in feeling unsteady and having balance problems $[4,36]$. There was some correlation between SOC and HRQL but no significant difference in SOC between dizzy and non-dizzy participants.

Approximately half of the study population reported problems with dizziness or unsteadiness (54\%), which is in line with previous reports from geriatric settings [37], but higher than previous research in Swedish settings
[1]. Dizziness tends to be more common with increasing age as well as with higher morbidity and may well be a sign associated with morbidity, also in younger ages [5]. Having dizziness, non-vertigo type, has been associated with higher mortality risk, compared to dizziness due to peripheral causes [38]. The most common duration of dizziness was seconds and symptoms triggered by raising up or by positional changes, symptoms often seen in orthostatic hypotension or benign paroxysmal positional vertigo (BPPV). Dizziness and imbalance are also often associated with fear of falling as well as sometimes can be part of aging and frailty [4, 18]. Here, we found that participants with dizziness showed a lower HRQL than those without, including when adjusting for underlying comorbidities. Women in general tend to report poorer health and HRQL and seek medical care more often compared to men, and are prescribed more medications [39] 40, however, similar sex differences were not distinctly observed here, possibly due to the high age of the participants.

Knowledge of the impact of dizziness on HRQL among older adults is of great importance because the overall well-being and activity level may be hampered and this population may risk isolation due to fear of going out alone, as well as frustration and decreased self-esteem $[17,41]$. Chronic dizziness may also lead to loss of confidence and restriction of physical and social activities to reduce risk of inconvenient symptoms.

The SF-36, although designed as a multidimensional tool to measure HRQL, targets mainly physical function and general health with less focus on mental health. The focus on function may be a reason why joint/back problems as well as vision impairment influenced HRQL so 
Table 5 Multivariable linear regression between different domains of SF-36 and SOC-13, gender, conditions and diseases

\begin{tabular}{|c|c|c|c|c|c|}
\hline SF-36 domain & Variable & Estimate & $\mathrm{Cl}$ & R-square & $p$ value \\
\hline \multirow[t]{7}{*}{ Physical functioning } & Intercept & 88.3 & & & \\
\hline & Female sex & -5.9 & $-10.2,-1.6$ & 0.24 & 0.007 \\
\hline & Dizziness & -6 & $-10.3,-1.6$ & & 0.007 \\
\hline & Diabetes & -10.7 & $-16.9,-4.4$ & & 0.0009 \\
\hline & Lung disease & -13.4 & $-19.7,-7.1$ & & $<0.0001$ \\
\hline & Vision impairment & -6.7 & $-11.1,-2.3$ & & 0.003 \\
\hline & Joint/back problem & -14.8 & $-19.5,-10.2$ & & $<0.0001$ \\
\hline \multirow[t]{5}{*}{ Role physical } & Intercept & 30.3 & & & \\
\hline & SOC -13 total score & 0.7 & $0.26,1.1$ & 0.14 & 0.001 \\
\hline & Heart disease & -12.8 & $-21.8,-4.0$ & & 0.005 \\
\hline & Vision impairment & -10.7 & $-18.8,-2.6$ & & 0.01 \\
\hline & Joint/back problem & -16.9 & $-25.1,-8.7$ & & $<0.0001$ \\
\hline \multirow[t]{5}{*}{ Bodily pain } & Intercept & 56.7 & & & \\
\hline & Dizziness & -8.2 & $-12.8,-3.6$ & 0.31 & 0.0005 \\
\hline & SOC -13 total score & 0.4 & $0.18,0.63$ & & 0.0004 \\
\hline & Vision impairment & -6.3 & $-11.0,-1.7$ & & 0.008 \\
\hline & Joint/back problem & -23 & $-28.5,-18.7$ & & $<0.0001$ \\
\hline \multirow[t]{7}{*}{ General health } & Intercept & 60.9 & & & \\
\hline & SOC-13 total score & 0.3 & $0.1,0.5$ & 0.36 & 0.0003 \\
\hline & Diabetes & -6.9 & $-11.8,-1.9$ & & 0.007 \\
\hline & Lung disease & -7.05 & $-12.1,-2.0$ & & 0.006 \\
\hline & Heart disease & -10.5 & $-14.4,-6.7$ & & $<0.0001$ \\
\hline & Vision impairment & -5.6 & $-9.0,-10.1$ & & 0.002 \\
\hline & Joint/back problem & -13.6 & $-17.1,-10.1$ & & $<0.0001$ \\
\hline \multirow[t]{6}{*}{ Vitality } & Intercept & 32.6 & & & \\
\hline & Dizziness & -6.4 & $-10.4,-2.4$ & 0.3 & 0.002 \\
\hline & SOC-13 total score & 0.7 & $0.5,0.9$ & & $<0.0001$ \\
\hline & Heart disease & -7.7 & $-12.1,-3.3$ & & 0.0008 \\
\hline & Vision impairment & -5.7 & $-9.8,-1.7$ & & 0.006 \\
\hline & Joint/back problem & -8.5 & $-12.7,-4.3$ & & $<0.0001$ \\
\hline \multirow[t]{3}{*}{ Social functioning } & Intercept & 45 & & & \\
\hline & SOC-13 total score & 0.6 & $0.4,0.8$ & 0.11 & $<0.0001$ \\
\hline & Joint/back problem & -9.2 & $-13.6,-4.7$ & & $<0.0001$ \\
\hline \multirow[t]{3}{*}{ Role emotional } & Intercept & 13.8 & & & \\
\hline & SOC-13 total score & 1 & $0.6,1.4$ & 0.1 & $<0.0001$ \\
\hline & Diabetes & -15.4 & $-26.3,-4.5$ & & 0.006 \\
\hline \multirow[t]{3}{*}{ Mental health } & Intercept & 11.7 & & & \\
\hline & SOC-13 total score & 1 & $0.8,1.1$ & 0.28 & $<0.0001$ \\
\hline & Joint/back problem & -5.8 & $-9.1,-2.5$ & & 0.0007 \\
\hline
\end{tabular}

Multivariable linear regression between different domains of Short form Health Survey questionnaire (SF-36) and sense of coherence (SOC-13), self-rated health (SRH), gender, conditions and diseases remaining after backward elimination process using exclusion criteria $p>0.01$

Predictors included in the first step of the backward selection were female sex, dizziness, Sense of Coherence (SOC total score), diabetes, hypertension, hyper or hypothyroidism, lung disease (chronic bronchitis, asthma, chronic obstructive pulmonary disease), cardiac infarction/heart failure, prior stroke, vision or hearing impairment and joint/back problems

much in this study. The MH and RE domains are the two domains in SF-36 that evaluate the mental health aspects, of which the SF-36 MH domain showed the strongest correlation with SOC. This indicates that dizziness and impaired balance are associated with decreased HRQL in older people in aspects of physical function and general health rather than in mental or psychological parts. The enhanced level of ADL-dependency also indicates a decline in functional aspects among persons with dizziness. 
Table 6 Mean scores of the different domains in the Short form Health Survey questionnaire (SF-36) divided by sex

\begin{tabular}{lcll}
\hline Mean $\left(\mathbf{S D}^{\mathrm{a}}\right)$ among women and men & & \\
\hline Domains & Total & Women & Men \\
& $\mathbf{n}=\mathbf{4 6 7}$ & $\mathbf{n}=\mathbf{2 8 4}$ & $\mathbf{n}=\mathbf{1 8 5}$ \\
\hline Physical functioning & $66.5(25)$ & $63.0(25)$ & $71.7(23)^{* *}$ \\
Role physical & $61.0(42)$ & $58.5(43)$ & $64.9(41)$ \\
Bodily pain & $65.1(27)$ & $61.4(27)$ & $70.9(27)^{* *}$ \\
General health & $63.5(21)$ & $62.9(21)$ & $64.4(20)$ \\
Vitality & $62.7(23)$ & $61.1(24)$ & $65.2(22)$ \\
Social functioning & $82.4(24)$ & $81.0(24)$ & $84.5(23)$ \\
Role emotional & $72.6(39)$ & $71.6(40)$ & $74.0(37)$ \\
Mental health & $79.0(19)$ & $76.7(21)$ & $82.6(17)^{*}$ \\
\hline
\end{tabular}

Mean scores of the different domains in the Short form Health Survey measuring health-related quality of life. The maximum score for SF-36 is 100 for every domain with higher scores indicating better health-related quality of life

a $S D$ standard deviation. $p$ values based on $t$ test comparing men and woman, ${ }^{*} p<0.05 ;{ }^{* *} p<0.01$

In line with the findings of Mendel et al. investigating patients with vestibular disorders, having dizziness was not associated with lower mean total SOC score [29] in this population-based sample. The salutogenetic concept includes and combines many aspects of quality of life, including phycological and interpersonal and personal resources. As dizziness is so associated with comorbidity and decreased SRH and HRQL, an association between dizziness and total SOC-score could be expected, however not the case. Potentially because $\mathrm{SOC}$ focuses on less functional aspects of quality of life and more on personality traits. Antonovsky hypothesized that a high SOC may be a resource in creating positive health and may work as a buffer against life stressors, possibly seen as a protecting capacity at least if good health is preserved [35, 42]. In this cohort of 79-years-old mainly ordinary-home-dwelling individuals, we found an overall high level of SOC, higher than in other surveys investigating older seniors [43] and higher than in a middle-aged Swedish group investigated previously [44]. Also, SF-36 was high in relation to other reference age-related groups [45]. This high level of SOC, together with the high level of SRH indicates that the cohort is generally healthy and report being satisfied with their health situation.

Finally, one has to consider HRQL and health as complex constructs, which are influenced by many factors. Having dizziness showed negative associations with HRQL, tiredness and SRH, but not with SOC, possibly indicates that dizziness in old age mainly is associated with a decline in the self-perceived health status or the functional abilities of the person.

\section{Strengths and limitations}

The strength of this study is the truly population-based sample selected through date of birth in the population registry. The examinations were performed by specially trained nurses or physicians. Due to the cross-sectional design of the study, the direction of the association cannot be established. No validated questionnaire for measuring dizziness were used Asking about both dizziness and unsteadiness in one question has some limitations as it results in asking two questions as one. Furthermore, the study is part of a multidisciplinary survey, which is why more participants completed the study questions about dizziness and general health than answered the validated SOC-13 $(\mathrm{n}=452)$ and SF-36 questionnaires $(\mathrm{n}=467)$.

\section{Conclusion}

Dizziness was negatively associated with HRQL, also after adjusting for comorbidities. Identification and treatment of dizziness, when possible, are important because reduction of dizziness symptoms may potentially help to enhance overall well-being in this age group.

\section{Acknowledgements \\ The authors thank Valter Sundh for statistical support}

\section{Authors' contributions}

EL, main author, responsible for design of the work and analyzing the data and writing of the manuscript. CF, responsible for design of the work, interpretation of the data, drafting and critically revising the work including statistical analyses. TK, writing author, responsible for design of the work, interpretation of the data and critically revising the manuscript. Mia Johansson, writing author, responsible for design of the work and critically revising the manuscript. LK, writing author, responsible analyzing and interpretation of the data and critically revising the manuscript. LR, responsible for study set up, data collection and analyzing the data and critically revising the manuscript. HFE, responsible for study set up, data collection and analyzing the data and critically revising the manuscript. MMF responsible for study set up, data collection and analyzing the data and critically revising the manuscript. IS responsible for study set up, data collection and analyzing the data and critically revising the manuscript. All authors have approved the final version of the manuscript to be published. All authors read and approved the final manuscript.

\section{Funding}

Open access funding provided by University of Gothenburg. The study was financed by grants from the Swedbank Sjuhärad foundation as well as Local Research and Development Council, Södra Älvsborg, the Amlöv's foundation, the Swedish state under the agreement between the Swedish government and the county councils, the ALF-agreement [Grant Number ALF716681]; the Swedish Research Council [Grant Numbers 2015-02830, 2013-8717]; Swedish Research Council for Health, Working Life and Wellfare [Grant Numbers 2008-1229, 2012-1138, 2006-0596, 2008-1111, 2010-0870, 2013-1202, and 2013-2300, and 2013-2496 to Centre for Aging and Health]; Swedish Brain Power; Konung Gustaf V:s och Drottning Victorias Frimurarestiftelse; Swedish Alzheimerfonden; Hjärnfonden; The Alzheimer's Association Zenith Award [Grant Number ZEN-01-3151]; The Alzheimer's Association Stephanie B. Overstreet Scholars [Grant Number IIRG-00-2159]; Stiftelsen Wilhelm och Martina Lundgrens vetenskapsfond; Stiftelsen Demensfonden; Handlanden Hjalmar Svenssons Forskningsfond; Eivind och Elsa K:son Sylvans stiftelse; Stiftelsen 
Söderström-Königska Sjukhemmet; Stiftelsen för Gamla Tjänarinnor; Stiftelsen Professor Bror Gadelius Minnesfond.

\section{Availability of data and materials}

Not applicable.

\section{Declarations}

\section{Ethics approval and consent to participate}

The study was conducted according to the Declaration of Helsinki and was approved by the Regional Ethical Review Board in Gothenburg, Sweden. All participants gave their informed written consent before inclusion in the study.

\section{Consent for publication}

All authors have read and approved the resubmission of the manuscript.

\section{Competing interests}

On behalf of all authors, the corresponding author states that there is no conflict of interest.

\begin{abstract}
Author details
${ }^{1}$ Department of Otorhinolaryngology, Head and Neck Surgery, Institute of Clinical Sciences, Sahlgrenska Academy, Sahlgrenska Universitetssjukhuset, Gothenburg University, Gröna Stråket 5, 41345 Gothenburg, Sweden. ${ }^{2}$ Department of Otorhinolaryngology, Region Västra Götaland, Sahlgrenska University Hospital, 41345 Gothenburg, Sweden. ${ }^{3}$ Department of Occupational Therapy and Physiotherapy, Institute of Clinical Sciences, Sahlgrenska Academy, Gothenburg University, 41345 Gothenburg, Sweden. ${ }^{4}$ Department of Oncology, Institute of Clinical Sciences, Sahlgrenska Academy, Gothenburg University, 41345 Gothenburg, Sweden. ${ }^{5}$ Neuropsychiatric Epidemiology Unit, Institute of Neuroscience and Physiology Sahlgrenska Academy, Centre for Ageing and Health (AgeCap), University of Gothenburg, Gothenburg, Sweden.
\end{abstract}

Received: 14 February 2021 Accepted: 15 September 2021

Published online: 02 October 2021

\section{References}

1. Jonsson R, Sixt E, Landahl S, Rosenhall U. Prevalence of dizziness and vertigo in an urban elderly population. J Vestib Res Equilib Orientat. 2004;14(1):47-52.

2. Fernandez $L$, Breinbauer HA, Delano PH. Vertigo and dizziness in the elderly. Front Neurol. 2015;6:144.

3. Grimby A, Rosenhall U. Health-related quality of life and dizziness in old age. Gerontology. 1995;41(5):286-98.

4. Kao AC, Nanda A, Williams CS, Tinetti ME. Validation of dizziness as a possible geriatric syndrome. J Am Geriatr Soc. 2001;49(1):72-5.

5. Tamber B. Self-reported faintness or dizziness - comorbidity and use of medicines. An epidemiological study. Scand J Public Health. 2009;37:613-20.

6. Sweden S. The future population of Sweden 2015-2060. Statistics Sweden. 2015.

7. Boelens C, Hekman EE, Verkerke GJ. Risk factors for falls of older citizens. Technol Health Care. 2013;21(5):521-33.

8. Lindell E, Kollén L, Johansson M, Karlsson T, Rydén L, Falk Erhag $H$, et al. Benign paroxysmal positional vertigo, dizziness, and health-related quality of life among older adults in a population-based setting. Eur Arch Otorhinolaryngol. 2021;278(5):1637-44.

9. Cummins RA, Lau AL, Stokes M. HRQOL and subjective well-being: noncomplementary forms of outcome measurement. Expert Rev Pharmacoecon Outcomes Res. 2004;4(4):413-20.

10. Testa MA, Simonson DC. Assessment of quality-of-life outcomes. N Engl J Med. 1996;334(13):835-40.

11. Moons P. Why call it health-related quality of life when you mean perceived health status? Eur J Cardiovasc Nurs. 2004;3(4):275-7.

12. Fayers PM. Quality of Life: the assessment, analysis and interpretation of patient-reported outcomes; 2007.
13. Hull SL, Kneebone II, Farquharson L. Anxiety, depression, and fall-related psychological concerns in community-dwelling older people. Am J Geriatr Psychiatry. 2013;21(12):1287-91.

14. Halaweha W, Grimby-Ekmanb S. Physical activity and health-related quality of life among community dwelling elderly. J Clin Med Res. 2015;7(11):845-52.

15. Weidt S, Bruehl AB, Straumann D, Hegemann SC, Krautstrunk G, Rufer M. Health-related quality of life and emotional distress in patients with dizziness: a cross-sectional approach to disentangle their relationship. BMC Health Serv Res. 2014;14:317.

16. Cheng YY, Kuo CH, Hsieh WL, Lee SD, Lee WJ, Chen LK, et al. Anxiety, depression and quality of life (QOL) in patients with chronic dizziness. Arch Gerontol Geriatr. 2012;54(1):131-5.

17. Ciorba A, Bianchini C, Scanelli G, Pala M, Zurlo A, Aimoni C. The impact of dizziness on quality-of-life in the elderly. Eur Arch Otorhinolaryngol. 2017;274(3):1245-50.

18. Lindell $E$, Kollén $L$, Johansson $M$, Karlsson $T$, Rydén $L$, Zettergren $A$, et al. Dizziness and its association with walking speed and falls efficacy among older men and women in an urban population. Aging Clin Exp Res. 2020;32(6):1049-56

19. Horder H, Skoog I, Frandin K. Health-related quality of life in relation to walking habits and fitness: a population-based study of 75-year-olds. Qual Life Res. 2013;22(6):1213-23.

20. Kollen L, Horder H, Moller C, Frandin K. Physical functioning in older persons with dizziness: a population-based study. Aging Clin Exp Res. 2017;29(2):197-205.

21. Ware JE, Sherbourne CD. The MOS 36-item short-form health survey (SF-36). I. Conceptual framework and item selection. Med Care. 1992;30(6):473-83.

22. DeSalvo KB, Fisher WP, Tran K, Bloser N, Merrill W, Peabody J. Assessing measurement properties of two single-item general health measures. Qual Life Res. 2006;15(2):191-201.

23. Jylha M. What is self-rated health and why does it predict mortality? Towards a unified conceptual model. Soc Sci Med. 2009;69(3):307-16.

24. Desalvo KB, Muntner P. Discordance between physician and patient selfrated health and all-cause mortality. Ochsner J. 2011;11(3):232-40.

25. Idler EL, Benyamini Y. Self-rated health and mortality: a review of twentyseven community studies. J Health Soc Behav. 1997;38(1):21-37.

26. Huohvanainen E, Strandberg AY, Stenholm S, Pitkala KH, Tilvis RS, Strandberg TE. Association of self-rated health in midlife with mortality and old age frailty: a 26-year follow-up of initially healthy men. J Gerontol A Biol Sci Med Sci. 2016;71(7):923-8.

27. Eriksson M, Lindstrom B. Antonovsky's sense of coherence scale and the relation with health: a systematic review. J Epidemiol Community Health. 2006;60(5):376-81.

28. Drageset J, Eide GE, Nygaard HA, Bondevik M, Nortvedt MW, Natvig GK. The impact of social support and sense of coherence on health-related quality of life among nursing home residents-a questionnaire survey in Bergen, Norway. Int J Nurs Stud. 2009;46(1):65-75.

29. Mendel B, Bergenius J, Langius A. The sense of coherence: a tool for evaluating patients with peripheral vestibular disorders. Clin Otolaryngol Allied Sci. 2001;26(1):19-24.

30. Green JD Jr, Verrall A, Gates GA. Quality of life instruments in Meniere's disease. Laryngoscope. 2007;117(9):1622-8.

31. Wallace M, Shelkey M. Katz index of independence in activities of daily living (ADL). Urol Nurs. 2007;27(1):93-4.

32. Sullivan M, Karlsson J, Ware JE. The Swedish SF-36 Health Survey-I. Evaluation of data quality, scaling assumptions, reliability and construct validity across general populations in Sweden. Soc Sci Med. 1995:41(10):1349-58.

33. Sullivan M, Karlsson J. The Swedish SF-36 Health Survey III. Evaluation of criterion-based validity: results from normative population. J Clin Epidemiol. 1998;51(11):1105-13.

34. Antonovsky A. The structure and properties of the sense of coherence scale. Soc Sci Med. 1993;36(6):725-33.

35. Eriksson M, Lindstrom B. Validity of Antonovsky's sense of coherence scale: a systematic review. J Epidemiol Community Health. 2005;59(6):460-6.

36. Chang J, Hwang SY, Park SK, Kim JH, Kim HJ, Chae SW, et al. Prevalence of dizziness and associated factors in South Korea: a cross-sectional survey from 2010 to 2012. J Epidemiol. 2018;28(4):176-84. 
37. Oghalai JS, Manolidis S, Barth JL, Stewart MG, Jenkins HA. Unrecognized benign paroxysmal positional vertigo in elderly patients. Otolaryngol Head Neck Surg. 2000;122(5):630-4.

38. van Vugt VA, Bas G, van der Wouden JC, Dros J, van Weert H, Yardley L, et al. Prognosis and survival of older patients with dizziness in primary care: a 10-year prospective cohort study. Ann Fam Med. 2020;18(2):100-9.

39. Craftman AG, Johnell K, Fastbom J, Westerbotn M, von Strauss E. Time trends in 20 years of medication use in older adults: findings from three elderly cohorts in Stockholm, Sweden. Arch Gerontol Geriatr. 2016;63:28-35.

40. Oksuzyan A, Juel K, Vaupel JW, Christensen K. Men: good health and high mortality. Sex differences in health and aging. Aging Clin Exp Res. 2008;20(2):91-102.

41. Dros J, Maarsingh OR, Beem L, van der Horst HE, ter Riet G, Schellevis FG, et al. Impact of dizziness on everyday life in older primary care patients: a cross-sectional study. Health Qual Life Outcomes. 2011;9:44

42. Wiesmann $\mathrm{U}$, Hannich $\mathrm{HJ}$. A salutogenic inquiry into positive aging-a longitudinal analysis. Aging Ment Health. 2018;56:1-7.

43. Drageset J, Espehaug B, Hallberg IR, Natvig GK. Sense of coherence among cognitively intact nursing home residents - a five-year longitudinal study. Aging Ment Health. 2014;18(7):889-96.
44. Festin K, Thomas K, Ekberg J, Kristenson M. Choice of measure matters: a study of the relationship between socioeconomic status and psychosocial resources in a middle-aged normal population. PLOS ONE. 2017;12(8):e0178929.

45. Ware JE, Jr. SF-36 Health survey. Manual and Interpretation Guide. The Health Institute, New England Medical Center; 1993.

46. Lindmark U, Stenstrom U, Gerdin EW, Hugoson A. The distribution of "sense of coherence" among Swedish adults: a quantitative cross-sectional population study. Scand J Public Health. 2010;38(1):1-8.

47. Silverstein $M$, Heap J. Sense of coherence changes with aging over the second half of life. Adv Life Course Res. 2015;23:98-107.

\section{Publisher's Note}

Springer Nature remains neutral with regard to jurisdictional claims in published maps and institutional affiliations.
Ready to submit your research? Choose BMC and benefit from:

- fast, convenient online submission

- thorough peer review by experienced researchers in your field

- rapid publication on acceptance

- support for research data, including large and complex data types

- gold Open Access which fosters wider collaboration and increased citations

- maximum visibility for your research: over $100 \mathrm{M}$ website views per year

At BMC, research is always in progress.

Learn more biomedcentral.com/submissions 